$\xi=-1$

\title{
Indoor Fungal Growth on Variable Antifungal at Different Wall Finishing on Plasterboard
}

\author{
N.M.Sunar ${ }^{1,3 *}$,M. Subramaniam ${ }^{2}$, N.F. Zulkifly ${ }^{2}$, U. K. Parjo ${ }^{1}$, C. M. Er ${ }^{2}$, A. M. Leman ${ }^{1,3}$, A. Khalid ${ }^{1,3}$, M.F. \\ Shaari $^{1,3}$, A.H. Abdul Rashid ${ }^{1,3}$, E. Zaidi ${ }^{4}$, A.T.S. Azhar ${ }^{2}$ \\ ${ }^{I}$ Faculty of Engineering Technology (FTK), Faculty of Engineering Technology, Universiti Tun Hussein Onn Malaysia, \\ Pagoh Higher Education Hub, KM 1, Jalan Panchor, 84600 Pagoh, Johor, MALAYSIA. \\ ${ }^{2}$ Faculty of Civil and Environmental Engineering (FKAAS), University Tun Hussein Onn, 86400, Parit Raja, \\ Batu Pahat, Johor, MALAYSIA. \\ ${ }^{3}$ Advanced Technology Centre (ATC), Faculty of Engineering Technology, Universiti Tun Hussein Onn Malaysia \\ Pagoh Higher Education Hub, KM 1, Jalan Panchor, 84600 Pagoh, Johor, MALAYSIA. \\ ${ }^{4}$ Faculty of Science, and Technology (FAST), Universiti Tun Hussein Onn Malaysia, Pagoh Higher Education Hub, \\ KM 1, Jalan Panchor, 84600 Pagoh, Johor, MALAYSIA. \\ *Corresponding author E-mail: shuhaila@uthm.edu.my
}

\begin{abstract}
Various health complaints often been attributed to pollution and the poor quality of the indoor air. If there is good practice in building design, construction, and maintenance, the structures should remain dry. However, when there is moisture damage, the materials may be in contact with water for prolonged times, which inevitably leads to microbial growth or even total deterioration of the building material. Antimicrobial coating is designed to generate a surface that is easy to clean and can also incorporate active agents, commonly called antifungal, that prevent microbial colonization, the subsequent growth and bio-deterioration of the substrate. This paper presents the sustainable treatment for indoor environment quality in buildings by examining the application of potassium sorbate, zinc salicylate, and calcium benzoate that used as food industry preservatives as indoor antimicrobial agents. Four types of wall finishing used on plasterboard substrate: acrylic paint, glycerol based-paint, thin wallpaper, and thick wallpaper. The result indicated that potassium sorbate is the best bio compound to react as antifungal agent to prohibit the growth of indoor fungi. All the antifungal shows difference level of their effectiveness from each other. Only $40 \%$ of fungi were able to grow on thin wallpaper by using potassium sorbate as antifungal agent.
\end{abstract}

Keywords: Use Antifungal, indoor air contamination, indoor air quality, plasterboard, wall finishing.

\section{Introduction}

Indoor air pollution is very dangerous as it poses health problems especially to the kids as their bodies is still developing and they breathe a higher volume of air relative to their body size [1-3, 4]. Some of the common symptoms due to the lack of proper air ventilation are runny nose, nasal congestion, eye irritation, cough, asthma aggravation, fatigue, headaches and difficulty in concentrating [5]. Factors such as temperature and relative humidity plays a major role in pollutant concentration thus affect the indoor air $[6,7]$. These indoor pollutants include fungi, mold, allergens and bacteria. Some of the materials used in construction industry such as ceiling tiles, wood, paint, and carpet rugs known for good environment for the growths of fungi. Application of antifungal coatings can prevent and protect the bio-deterioration of the substrates in buildings [8].

The antifungal used should be effective in controlling the fungi growth and safe consumed as concerns rises on the safety of the chemicals used [9]. Antifungal such as potassium sorbate, calcium benzoate and zinc salicylate is safe as food preservatives [1, 1012]. Therefore, this research conducted to investigate the ability of these antifungal to reduce the growth of indoor fungi on four dif- ferent types of wall finishing. Thus, it is aimed to determine the best application of these antifungal as protective layer on the four types of wall finishing.

\section{Materials and Methods}

\subsection{Preparation of Indoor fungi Spore}

The spores from the cultures transferred to spore suspension Tween $20(0.005 \%-\mathrm{w} / \mathrm{v})$, sodium chloride $(0.85 \%-\mathrm{w} / \mathrm{v})$ and distilled water $(200 \mathrm{ml})$ used to prepare spore suspension according to Bellotti, et al. [9]. The spore suspension was prepared from the subculture. By using Neubauer chamber, the concentration of spores then was adjusted to approximately $0.3-0.5 \times 106$ spores $/ \mathrm{ml}$ $[1,7,8,12]$.

\subsection{Preparation of Bio-Resistance Test}

The sample preparation steps was referred based on Vacher et al. [13] and Bellotti et al., [9] studies. The plasterboard cut into total 16 pieces. Each piece was approximately $5 \mathrm{~cm}$ x $5 \mathrm{~cm}$. Each type of wall finishing consists of 4 pieces of plasterboard. One sample used as control and the other three samples were applied with 
antifungal. Each of the samples washed with $70 \%$ of ethanol and allowed to dry for 24 hours before application. Two types of wallpaper were used which are thick (THICK W) and thin wallpaper (THIN W) while paint used in this study was acrylic paint (AP) and glycerol-based paint (GBP). For treatment samples, approximately 0.03 grams of potassium sorbate mixed with $100 \mathrm{ml}$ of distilled water before applying onto wallpapers surface. For control samples, no antifungal added to the samples.

The same steps repeated with zinc salicylate, and calcium benzoate as antifungal. The $(5 \mathrm{~cm} \times 5 \mathrm{~cm})$ size sample each then covered with a layer of paint respectively and some glued with wallpapers onto substrate support. All samples dried under laboratory condition for 24 hours before inoculating with indoor fungal spores. All the samples irradiated with UV-light for 40 minutes to avoid contamination before inoculating with fungal spores. Pipette used to inject the indoor fungal spore onto the sample surface and the spore spread with cotton buds.

The sample placed in the petri dish containing malt extract agar (MEA) agar for 27 days of incubation period in a laboratory at $30^{\circ} \mathrm{C}$ for observation. Degree of indoor fungal growth measured according to the scale provided by American Society for Testing and Materials ASTM D5590-00 standard.

Table 1 Scale for evaluation indoor fungal growth (ASTM D5590-00 Standard Scale) [15]

\begin{tabular}{|c|c|c|}
\hline Scale & Percentage of Fungi Growth & Degree of Fungi Growth \\
\hline $\mathbf{0}$ & 0 & None trace of growth \\
\hline $\mathbf{1}$ & $(<10 \%)$ & Trace Growth \\
\hline $\mathbf{2}$ & $(10-30 \%)$ & Light growth \\
\hline $\mathbf{3}$ & $(30-60 \%)$ & Moderate growth \\
\hline $\mathbf{4}$ & $(60-100 \%)$ & Heavy growth \\
\hline
\end{tabular}

The tests that conducted in laboratory, several parameters recorded to determine the factors affect the rate of mold growth. The physical parameters that are diameter, rating, and percentage referred according to ASTM D5590-00 [15]. The data analysed for free-antifungal substrate and antifungal-applied substrate that consist of difference wall finishing. As the results, the efficiency of the various antifungal in treating the indoor fungal are observed by the rate of the indoor fungal growth until Day 27 .

\section{Results and Discussion}

The bar graph for overall indoor fungal growth on plasterboard treated by potassium sorbate shown (Fig.1). Acrylic paint shown to have the highest growth percentage that is $100 \%$ on Day 27 , followed by glycerol-based paint with $83 \%$. The growth of indoor fungi found on thick wallpaper was $47 \%$ and on thin wallpaper was the growth by $40 \%$ on the 27 th day. Thus, thin wallpaper is effective compared to other types of wall finishing on potassium sorbate treatment as antifungal agent. Acrylic paint has the bigger percentage of indoor fungal growth due to different chemical contains in each paint. It might affect the effectiveness of potassium sorbate as an antifungal agent.

On the other hand, the overall percentage of indoor fungal growth on different wall finishing treated by calcium benzoate shown (Fig. 2 ). The highest percentage of indoor fungal growth found on acrylic paint that rose dramatically from Day 6 to Day 9 at 100\%. However, it becomes constant after Day 12. Glycerol based pain was observed to have uniform growth of indoor fungi from Day 6 .

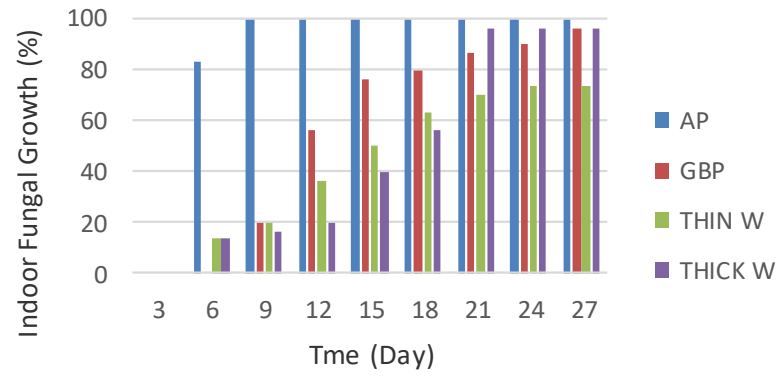

Fig. 1: The percentage of indoor fungal growth in variable wall finishing treated by potassium sorbate

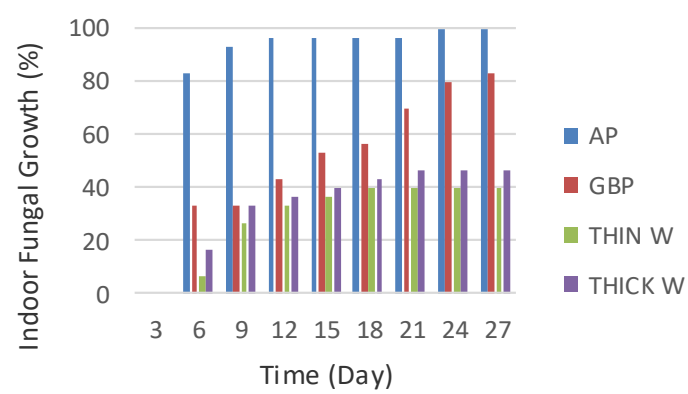

Fig. 2: The percentage of indoor fungal growth in variable wall finishing treated by calcium benzoate.

Thick and thin wallpaper too shows the uniform growth of fungi. Eventually, calcium benzoate is effective as an antifungal agent on thin wallpaper compared to other wall finishing by $78 \%$ at Day 27. This is because the application of calcium benzoate on thin wallpaper covers the top layer of the wallpaper and penetrates deep into it. The overall percentage of indoor fungal growth on different wall finishing of plasterboard treated by zinc salicylate shown (Fig. 3).

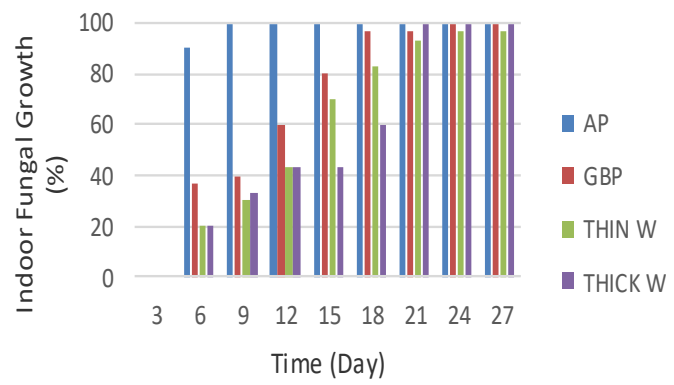

Fig. 3: The percentage of indoor fungal growth in variable wall finishing treated by zinc salicylate.

The percentage of fungi growth on acrylic paint achieved $100 \%$ by Day 9. Glycerol based paint and thick wallpaper shares the same percentage of fungi growth that is $97 \%$ on Day 27 . Thin wallpaper is the best medium to apply with zinc salicylate as it showed the lowest growth of fungi by Day 27. While the less effective wall finishing is the acrylic paint as the fungi achieved its maximum growth by Day 9 on this wall finishing. This is because the efficiency of acrylic paint is influenced by the humidity and temperature of its surrounding when applied [16-17]. The temperature of indoor environment mainly influences growth of indoor fungal. 
The maximum growth of indoor fungal attained at the temperature of $25^{\circ} \mathrm{C}$ to $30^{\circ} \mathrm{C}$ [18]. As for this study, all the samples incubated in $30^{\circ} \mathrm{C}$ temperature. Although all the samples were stored at $67 \%$ of relative humidity, this study proved it is suitable condition for indoor fungal growth.

\section{Conclusion}

Indoor fungi are dangerous growth formed inside the buildings at suitable temperature and relative humidity. Their presences post threat to the occupants or users of the room. Therefore, they must be eradicated. The fastest growth of indoor fungi on plasterboardbased material with four wall finishing marked rapid growth as on acrylic paint, followed by glycerol based paint and thick wallpaper. The slowest fungi growths for all the samples found on thin wallpaper. It suggested that antifungal added to avoid indoor fungi from growing and to act as a protective layer for the wall finishing. In this case, the best antifungal is potassium sorbate; and the best application is the potassium sorbate-treated thin wallpaper on plasterboard. Fungi inhibited to grow by only $40 \%$ until Day 27 of the study on thin wallpaper by using potassium sorbate as antifungal. This concludes that the exponential fungi growth phase able to be interrupted by potassium sorbate. It is recommend the use of biological antifungal should implemented in wall finishing of a building as it is proven in its effectiveness on plasterboard substrate.

\section{Acknowledgement}

The authors greatly appreciate Universiti Tun Hussein Onn Malaysia for facilitating the work and National Institute of Occupational Safety and Health, Ministry of Human Resource, Malaysia for providing technical assistance.

\section{References}

[1] Er C.M., Sunar N.M., Leman A.M., Othman N., Gani P., Jamal N.A., Emparan Q., Parjo U.K. (2015). In Vitro Inhibitory Assay of an Isolated Indoor Airborne Fungus from an Institutional Building of Computer Education by Using Potassium Sorbate. Applied Mechanics and Materials Vols 773-774, pp 1091-1095.

[2] Er C.M., Sunar N.M., Leman A.M., Othman N., Emparan Q., Parjo U.K., Gani P., Jamal N.A., Ideris N.A (2015). The Evaluation of Indoor Microbial Air Quality in Two New Commissioning Higher Educational Buildings in Johor, Malaysia. Applied Mechanics and Materials Vols. 773-774, pp 1068-1072.

[3] Chin Ming Er, N.M. Sunar, A.M. Leman, N. Othman (2015). Direct growth inhibition assay of total airborne fungi with application of biocide-treated malt extract agar. MethodsX 2, 340-344.

[4] Stafford, T. M. (2015). Indoor air quality and academic performance. Journal of Environmental Economics and Management, 70 34-50.

[5] Mentesea, S., Nihal A. Miricib, Muserref T. Otkunc, Coskun Bakard, Elif Palaza, Deniz Tasdibia, Sibel Cevizcid, Osman Cotuker. (2015). Association between respiratory health and indoor air pollution exposure in Canakkale, Turkey. Building and Environment (2015), 72-83

[6] Jo, W. J., and Sohn, J. Y. (2009). The effect of environmental and structural factors on indoor air quality of apartments in Korea. Building and Environment, 44(9), 1794-1802.

[7] Parjo, U.K., N. M. Sunar, A.M. Leman, P. Gani, Q. Emparan, E.C.Ming. (2015). In- Vitro Indoor Fungal Treatment On Wood By Using Potassium Sorbate As Biocide. Journal of Occupational Safety and Health, in press.

[8] Parjo, U. K., Sunar, N. M., Leman, A. M., Ideris, N. I. A., Gani, P. Emparan, Q., Er, C. M. (2015). Indoor Fungal Treatment by Using Potassium Sorbate as Bio-Resistance Coating for Different Plasterboard Wall Finishings. In Applied Mechanics and Materials (Vol 773, pp. 1116-1120)

[9] Bellottia, N., L. Salvatorea, C. Deyáa,M.T. Del Pannob, B. del Amoa, R. Romagnolia (2013). The application of bioactive compounds from the food industry to control mold growth in indoor waterborne coatings. Colloids and Surfaces B: Biointerfaces 140144

[10] Pereira, E. P. R., Faria, J. D. A. F., Pinto, U. M. (2013). Optimizing the use of potassium sorbate and sodium metabisulphite for the chemical and microbial stability of carbonated coconut water. Brazilian Journal of Food Technology, 16(2), 125-132.

[11] Hwang. C. A and Huang. L. (2014). The effect of Potassium Sorbate and $\mathrm{pH}$ on the growth of Listeria Monocytogenes in Ham Salad. Journal of Food Processing and Preservation 38, pp. 1511-1516

[12] Er, C. M., Sunar, N. M., Leman, A. M., Othman, N., Kalthsom, U., Jamal, N. A., \& Ideris, N. A. (2016). The biocidal effect of potassium sorbate for indoor airborne fungi remediation. Desalination and Water Treatment, 57(1), 288-293.

[13] Vacher, S., Hernandez, C., Bärtschi, C., \& Poussereau, N. (2010). Impact of paint and wallpaper on mould growth on plasterboards and aluminum. Building and Environment, 45(4), 916-921.

[14] Parjo, U. K., Sunar, N. M., Leman, A. M., Gani, P., Emparan, Q., \& Er, C. M. (2015). Coating Bio-Resistance Test of Different Wall Finishing for Isolated Indoor Fungal Treatment by Using Potassium Sorbate Biocide on Wood. In-Applied Mechanics and Materials (Vol. 773, pp. 1384-1388).

[15] ASTM D5590-00 (no. Reapproved 2013, 2014). Standard Test Method for Determining the Resistance of Paint Films and Related Coatings to Fungal Defacement by Accelerated Four-Week Agar Plate Assay. ASTM D5590 - 00, pp. 4-7.

[16] Anthony V. Arundel, E. M. (1986). Indirect Health Effects of Relative Humidity in Indoor Environments. Environmental Health Perspectives Vol. 65, pp. 351-361

[17] Norhidayah, A., Chia-Kuang, L., Azhar, M. K., \& Nurulwahida, S. (2013). Indoor air quality and sick building syndrome in three selected buildings. Procedia Engineering, 53, 93-98.

[18] Er C.M., Sunar N.M., Leman A.M., Norzila O., Emparan Q., Kalthsom U., Gani P., Jamal N.A (2014). Evaluation of Potassium Sorbate as a Biocide to Reduce Viability of Total Airborne Fungi in a Higher Educational Building of Computer Studies. Advanced Research in Materials Science Vol. 2, No.1, Pages 15-19. 